\title{
Anterior colporrhaphy does not induce bladder outlet obstruction
}

\author{
M. M. E. Lakeman • R. A. Hakvoort • \\ E. P. Van de Weijer • M. H. Emanuel • \\ J. P. W. R. Roovers
}

Received: 8 August 2011 / Accepted: 25 January 2012 /Published online: 8 February 2012

(C) The Author(s) 2012. This article is published with open access at Springerlink.com

\begin{abstract}
Introduction and hypothesis We aimed to evaluate if anterior colporrhaphy causes incomplete voiding due to bladder outlet obstruction.

Methods Women scheduled for anterior colporrhaphy were asked to undergo multichannel urodynamic investigation before surgery and the first postoperative day. Bladder outlet obstruction was assessed using the Blaivas-Groutz voiding nomogram. Maximum flow rate, detrusor pressure and residual volume were compared between pre- and postoperative measurements and between women with and without an abnormal post-void residual volume (PVR; volume exceeding $150 \mathrm{ml}$ ).

Results Seventeen women participated. One woman who was unobstructed before surgery was obstructed after surgery. Overall, detrusor pressure and maximum flow rate before and after surgery did not differ. After surgery, six women had an abnormal PVR, one was unable to void, four were mildly obstructed and one moderately obstructed. Conclusion Urodynamic investigation the first day after anterior colporrhaphy did not show that anterior colporrhaphy induces bladder outlet obstruction. The explanation for
\end{abstract}

M. M. E. Lakeman $(\bowtie) \cdot J$. P. W. R. Roovers

Department of Obstetrics and Gynaecology,

Academic Medical Centre,

Room H4-205, PO Box 22700, 1105 DE Amsterdam,

The Netherlands

e-mail: m.m.lakeman@amc.uva.nl

R. A. Hakvoort · M. H. Emanuel

Department of Obstetrics and Gynaecology, Spaarne Hospital,

Hoofddorp, The Netherlands

E. P. Van de Weijer

Department of Urology, Spaarne Hospital,

Hoofddorp, The Netherlands postoperative urinary retention can therefore also lie in nonanatomical causes such as postoperative pain and psychological factors.

Keywords Bladder outlet obstruction · Prolapse surgery . Urinary retention $\cdot$ Urodynamics

\section{Introduction}

Vaginal prolapse surgery is intended to restore normal pelvic floor function by correcting anatomical abnormalities. One of the most common complications directly related to prolapse surgery is the occurrence of incomplete emptying of the bladder [1]. Whereas the optimal management is assessed in several studies, the underlying pathophysiology of voiding difficulties after vaginal prolapse surgery is poorly understood [2].

Several hypotheses can be raised like impairment of bladder function and pelvic floor relaxation due to postoperative pain and anxiety [3]. Other frequently raised hypotheses have been urethral obstruction by oedema or hematoma formation and surgical damage to the innervation of the bladder [4]. As incomplete voiding is generally short lasting, it is questionable whether innervation damage plays an important role and thus obstruction related to oedema formation is a more acceptable explanation [5]. Until now, no studies have been undertaken to objectify the occurrence of bladder outlet obstruction following anterior colporrhaphy.

Previous studies have indicated that a combination of clinical parameters and urodynamic findings is the best way to define bladder outlet obstruction [6]. During urodynamics, flow rate and detrusor pressure are measured simultaneously and together they provide insight in whether obstruction is present as indicated by a relatively low flow 
rate related to the measured detrusor pressure $[3,4,6,7]$. Therefore, urodynamic studies were performed on patients before and after surgery in a prospective observational study to assess if anterior colporrhaphy is a risk factor for postoperative bladder outlet obstruction.

\section{Materials and methods}

A prospective study was performed in the Spaarne Hospital, Hoofddorp, the Netherlands. Women aged 18 years and older and who were scheduled for anterior colporrhaphy were informed about the study and asked to participate. Anterior repair could be combined with posterior repair and/or vaginal hysterectomy, sacrospinous ligament fixation or Manchester repair. Patients who were diagnosed with any neurological or anxiety disorder for which they underwent professional treatment and patients undergoing concomitant incontinence surgery were excluded.

The study was approved by the regional medical ethics committee (VU Academic Medical Centre, Amsterdam) and by the institutional medical ethical committee. After informed consent was obtained, patients underwent multichannel urodynamic investigation within 2 weeks before surgery and between 12 and $24 \mathrm{~h}$ after surgery.

During the study period, the participants completed a standardised urogynaecologic interview. Baseline characteristics and procedures performed were collected from all women.

\section{Urodynamic investigations}

Before urodynamics, urine analysis and culture were performed to rule out significant bacteriuria (defined as more than $10^{5}$ colony-forming units) and cystitis (defined as bacteriuria with at least one of the following additional complaints: lower abdominal pain, dysuria or fever). In case of urinary tract infection, patients were excluded to minimise the chance of urodynamic artefacts and interference by urinary tract infection. Prior to the pressure flow studies, patients were asked to empty their bladders; after which, the bladder was drained by a hydrophilic-coated transurethral catheterisation (SpeediCath ${ }^{\circledR}$, Amersfoort, the Netherlands).

Subsequently, pressure flow studies were performed using a MMS UD 2000 device (Medical Measurement Systems MMS, Enschede, Netherlands) with a water-filled MediPlus 5716 double-lumen cystometry catheter and a water-filled MediPlus 5415 rectal pressure balloon catheter.

Filling of the bladder occurred with saline at body temperature with a speed of $50 \mathrm{ml} / \mathrm{min}$ up to the moment patients experienced a strong desire to void or either filling continued up to a maximum volume equalling the functional bladder capacity which was defined as the largest voided volume in a 24 -h voiding a sitting position with the $7 \mathrm{~F}$ catheter in place. The post-void residual volume (PVR) was calculated by bladder catheterisation. Patients with a post-void bladder volume exceeding $150 \mathrm{ml}$ were diagnosed as having an abnormal PVR.

\section{Surgery}

Anterior colporrhaphy was performed using a midline incision of the vaginal epithelium, and the bladder was sharply dissected from the vaginal wall. The pubocervical fascia was plicated in the midline with absorbable Vicryl ${ }^{\circledR}$ 2-0 interrupted sutures (Ethicon Inc, Somerville, NJ, USA). The surplus of vaginal epithelium was removed, and the epithelium was closed with running absorbable interlocking Vicryl 2-0.

All procedures were performed in the same hospital and were performed by two gynaecologists with a special interest in urogynaecology. All procedures were performed under spinal analgesia. Patients received postoperative prophylaxis for deep vein thrombosis and a single dose of intravenous prophylactic antibiotics during surgery. A 14 French Foley indwelling catheter with a $5-\mathrm{ml}$ balloon was used to drain the bladder after surgery. This catheter was removed within $24 \mathrm{~h}$ on the morning of the first day after surgery.

\section{Postoperative care}

Postoperative care was standardised for all patients. A vaginal gauze was inserted directly after surgery. The catheter and gauze were removed on the morning of the first postoperative day. After the first attempt to void, patients underwent catheterisation of the bladder and subsequently pressure flow studies were performed (see "Urodynamic investigations" section). Patients with a PVR above $150 \mathrm{ml}$ received additional transurethral indwelling catheterisation for the duration of 3 days.

\section{Outcome measurements}

The primary outcome was the presence and extent of obstruction before and after surgery as defined by the Blaivas and Groutz nomogram $[6,8]$. In this nomogram, the maximum flow rate $\left(Q_{\max }\right)$ is plotted in relation to the maximum detrusor pressure $\left(P_{\text {detmax }}\right)$ (obtained from the pressure flow study). Four categories of obstruction have been defined: no, mild, moderate and severe obstruction. The boundaries of the four categories are as follows:

- Between no obstruction and mild obstruction: a line with slope 1.0 and intercept $7 \mathrm{~cm} \mathrm{H} 2 \mathrm{O}$

- Between mild and moderate obstruction a horizontal line at $P_{\text {detmax }}$ of $57 \mathrm{~cm} \mathrm{H} 2 \mathrm{O}$

- Between moderate and severe obstruction a horizontal line at $P_{\text {detmax }}$ of $107 \mathrm{~cm} \mathrm{H} 2 \mathrm{O}$ 
Secondary outcomes were differences in maximum flow rate, maximum detrusor pressure, maximum detrusor pressure during maximum flow rate and residual volume preand postoperatively in the total group and between women with and without abnormal PVR. A subanalysis was performed in women with abnormal PVR to compare the preand postoperative measurements.

\section{Statistical analysis}

Data were analysed in SPSS version 18.0. Continuous variables were analysed using the Wilcoxon's test for dependent data (i.e. differences between pre- and postoperative measurements) and a Mann-Whitney test for independent data. For categorical variables, Fisher exact or chi-square test was used.

\section{Results}

During the study period, 17 women underwent urodynamic investigation before and after anterior colporrhaphy was performed. Baseline characteristics and concomitantly performed procedures are summarised in Table 1.

Figure 1 shows the Blaivas and Groutz nomogram before and after surgery. The presence and degree of pre- and

Table 1 Patient characteristics, performed procedures and operative characteristics of the women who underwent pre- and postoperative pressure flow studies

\begin{tabular}{ll}
\hline & $N=17$ \\
\hline Patient characteristics & \\
Age (years) & $61.2(38.3-76.8)$ \\
Parity $(n)$ & $3(2-8)$ \\
BMI $\left(\mathrm{kg} / \mathrm{m}^{2}\right)$ & $26.7(22.4-32.2)$ \\
Previous gynaecological procedures & \\
Hysterectomy & $2(12)$ \\
POP-Q & \\
Ba & $0(-0.5-1.5)$ \\
Bp & $-2.6(-3.0-0.0)$ \\
C & $-2.4(-5.0-0.0)$ \\
Performed procedure & \\
Anterior colporraphy only (AC) & $11(65)$ \\
AC + sacrospinous ligament fixation & $1(6)$ \\
AC + posterior colporrhaphy (PC) & $3(18)$ \\
AC + Manchester Fothergill & $1(6)$ \\
AC + Manchester Fothergill + PC & $1(6)$ \\
Operative characteristics & \\
Duration of surgery (min) & $32.0(25.0-78.0)$ \\
Surgical complications & $0(0)$ \\
Postoperative complications & $0(0)$ \\
\hline
\end{tabular}

Values are numbers (percentage) or median (range)

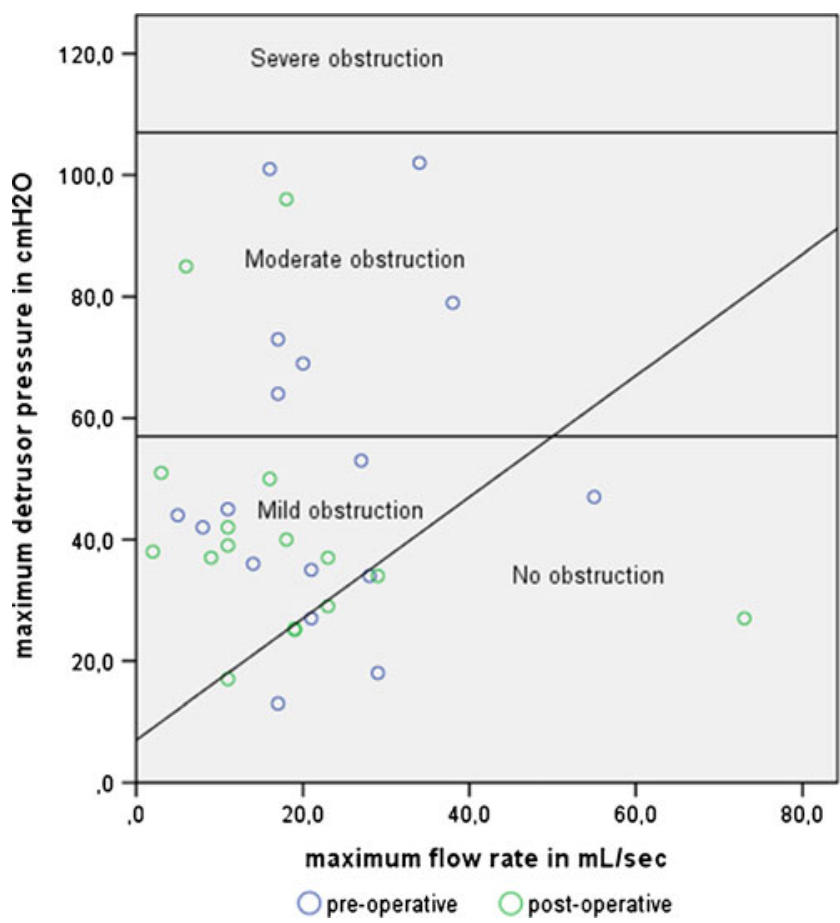

Fig. 1 Blaivas and Groutz nomogram. Distribution of the maximum flow rate by maximum detrusor pressure before and after vaginal prolapse surgery was performed

postoperative bladder outlet obstruction are summarised in Table 2. Overall, before surgery, five women were unobstructed, one of them had de novo mild bladder outlet obstruction; she underwent anterior colporrhaphy and had a residual volume after voiding of $121 \mathrm{ml}$. Twelve women were obstructed preoperatively, two of them were no longer obstructed after surgery. From the ten women who had preand postoperative bladder outlet obstruction, one woman increased in degree of obstruction from mild to moderate. She underwent anterior and posterior colporrhaphy and had a residual volume of $441 \mathrm{ml}$.

Table 3 shows the urodynamic findings before and after surgery. No statistical significant differences were found between the pre- and postoperative measurements.

Postoperatively, six women had an abnormal PVR (range, 172-487 ml). All of these six patients received a transurethral indwelling catheter which was removed after 3 days. All patients showed a residual volume under our definition of abnormal residual volume of $150 \mathrm{ml}$ after removal of this catheter. Of the six women with an abnormal PVR, one could not void at all, four women were classified as mildly obstructed and one woman as moderately obstructed according to the Blaivas and Groutz nomogram. One of these six women also had an abnormal PVR before surgery, the others not. Two of the six women underwent anterior and posterior colporrhaphy, the others anterior colporrhaphy only. Table 4 shows the postoperative urodynamic findings in these women compared to women with 
Table 2 Classification of obstruction according to the Blaivas and Groutz nomogram before and after surgery was performed

Postoperative situation

\begin{tabular}{|c|c|c|c|c|c|c|}
\hline & & & \\
\hline & & & No obstruction & Mild obstruction & Moderate obstruction & Severe obstruction \\
\hline \multirow[t]{4}{*}{ Preoperative situation } & No obstruction & $5(29 \%)$ & 4 & 1 & 0 & 0 \\
\hline & Mild obstruction & $6(35 \%)$ & 0 & 5 & 1 & 0 \\
\hline & Moderate obstruction & $6^{\mathrm{a}}(35 \%)$ & 2 & 2 & 1 & 0 \\
\hline & Severe obstruction & $0(0 \%)$ & 0 & 0 & 0 & 0 \\
\hline \multicolumn{2}{|l|}{ Total } & 17 & 6 & 8 & 2 & 0 \\
\hline
\end{tabular}

${ }^{\text {a }}$ One patient was not able to void postoperatively

a normal PVR. Women with abnormal PVR had a statistically significant lower maximum flow rate. No difference was found in maximum detrusor pressure. When performing a subanalysis comparing urodynamics before and after surgery among women with abnormal PVR, no statistically significant differences were found in maximum detrusor pressure, maximum detrusor pressure at maximum flow and maximum flow rate (data not shown).

\section{Discussion}

Our study was intended to explore if anterior colporrhaphy causes bladder outlet obstruction. Using urodynamic investigations shortly before surgery and on the first day after surgery, we could not reveal any difference in the presence of bladder outlet obstruction, the degree of obstruction, detrusor pressure and maximum flow rate. De novo obstruction after anterior colporrhaphy was only found in one woman, questioning the contribution of bladder outlet obstruction to the development of incomplete voiding following anterior colporrhaphy.

Table 3 Comparison of the median maximum flow rate $\left(Q_{\max }\right)$, maximum detrusor pressure $\left(P_{\text {detmax }}\right)$, maximum detrusor pressure during maximum flow rate $\left(P_{\operatorname{det} \text { max }}\right)$, residual volume and flow time as obtained by pressure flow studies before and after surgery

\begin{tabular}{llll}
\hline & $\begin{array}{l}\text { Before surgery, } \\
n=17\end{array}$ & $\begin{array}{l}\text { After surgery, } \\
N=16^{\mathrm{a}}\end{array}$ & $P^{\mathrm{b}}$ \\
\hline Voided volume (in mL) & $364.0(3.0-712.0)$ & $338.0(7.0-588.0)$ & 0.38 \\
$Q_{\max }$ (in mL/s) & $20.0(5.0-55.0)$ & $17.0(0.0-73.0)$ & 0.36 \\
$P_{\text {detQmax }}$ (in cm H2O) & $22.0(0.0-73.0)$ & $26.0(0.0-69.0)$ & 0.80 \\
$P_{\text {detmax }}$ (in cm H2O) & $44.0(13.0-102.0)$ & $37.5(17.0-96.0)$ & 0.53 \\
Residual volume (in mL) & $10.0(0.0-707.0)$ & $66.0(0.0-487.0)$ & 0.78 \\
Flow time (in s) & $49.5(28.0-222.0)$ & $58.0(9.0-255.0)$ & 0.65 \\
\hline
\end{tabular}

Values are median (range)

${ }^{a}$ One patient was unable to void during pressure flow studies after surgery

${ }^{\mathrm{b}}$ As calculated using Wilcoxon signed-ranks test
Before further interpreting the data, some issues need to be discussed. First is the relatively low number of patients included. For the diagnosis of obstruction, generally a $Q_{\max }<12 \mathrm{ml} / \mathrm{s}$ is required [7]. In the preoperative situation, median maximum flow rate was $20 \mathrm{ml} / \mathrm{s}$; therefore, we needed to be able show an $8-\mathrm{ml} / \mathrm{s}$ difference to be able to show if prolapse surgery caused bladder outlet obstruction. According to a post hoc analysis, this study would have $80 \%$ power to pick up a mean difference in maximum flow rate of $>7.7 \mathrm{ml} / \mathrm{s}$ between pre- and postoperative situation. Therefore, we are confident that we were able to pick up relevant differences with this small sample size. Furthermore, since no previous studies are performed evaluating bladder outlet obstruction, the first intention of our study was to explore if we could find any evidence that the inability to void on the first postoperative day was caused by bladder outlet obstruction possibly caused by oedema or hematoma formation. Even with our limited sample size, we could not reveal any indication that this was the case; therefore, we think it is unethical to expose more women to this investigation.

Second, one can argue about the timing of removal of the catheter and the consequent assessment of voiding parameters by postoperative pressure flow study. We decided to

Table 4 Comparison of postoperative median maximum flow rate $\left(Q_{\max }\right)$, maximum detrusor pressure $\left(P_{\text {detmax }}\right)$, maximum detrusor pressure during maximum flow rate $\left(P_{\operatorname{det} \text { max }}\right)$, residual volume and flow time between women with and without abnormal PVR

\begin{tabular}{lccc}
\hline & Normal PVR, $n=11$ & $\begin{array}{l}\text { Abnormal PVR, } \\
N=6^{\mathrm{a}}\end{array}$ & $P^{\mathrm{b}}$ \\
& & $98.0(7.0-206.0)$ & 0.01 \\
\hline Voided volume & $406.0(116.0-588.0)$ & $9.0(2.0-11.0)$ & 0.00 \\
$Q_{\max }$ (in mL/s) & $19.0(11.0-73.0)$ & $14.0(0.0-69.0)$ & 0.32 \\
$P_{\text {detQmax } \text { (in cm H2O) }}$ & $32.0(10.0-45.0)$ & $39.0(37.0-85.0)$ & 0.15 \\
$P_{\text {detmax } \text { (in cm H2O) }}$ & $34.0(17.0-96.0)$ & $392.0(305.0-707)$ & 0.00 \\
Residual volume (in mL) & $0.0(0.0-141.0)$ & $82.0(9.0-255.0)$ & 0.74 \\
Flow time (in s) & $54.0(35.0-108.0)$ & &
\end{tabular}

${ }^{a}$ One patient was unable to void during pressure flow studies after surgery

${ }^{\mathrm{b}}$ As calculated using Mann-Whitney $U$ test 
remove the catheter within the first day after surgery because several studies have shown benefits regarding UTI risk and catheterisation duration of this regimen [9-11]. This is therefore the timing at which incomplete voiding is most commonly identified and therefore the most clinically relevant timing when intending to study if bladder outlet obstruction plays a role in the development of this complication.

All included women underwent anterior colporraphy. Concomitant surgery included suspension techniques for uterine descent (two patients), posterior colporraphy (three patients) and a combination of both in one patient. Suspension techniques and elevation of the apical portion of the vagina have been reported to be a risk factor for abnormal PVR [12]. The most likely explanation for this finding is extra elevation of the bladder outlet and therefore obstruction. From our data, we could not confirm that obstruction according to the Blaivas and Groutz nomogram increased in the three patients with concomitant uterine suspension. Two studies have shown a risk increase with the performance of posterior compartment surgery. As this type of surgery has no anatomical relationship with the bladder, it has been hypothesised that pain and a disturbed relaxation of the pelvic floor might be a contributing factor in these cases $[13,14]$. In our study in one of the three patients with concomitant posterior repair obstruction according to the Blaivas and Groutz nomogram increased from mild to moderate, one patient could not void after surgery and the last patient remained unaltered. This does not exclude that posterior colporraphy might increase the risk of abnormal PVR due to the previously mentioned hypothesis. However, due to the small numbers, no definite conclusions can be drawn.

We chose to use pressure flow studies to assess bladder outlet obstruction since this is the best defined way to assess obstruction [4]. One might argue that video urodynamics has the advantage of also localising a possible obstruction; however, other studies have shown that using cutoff points in pressure flow studies compares favourably to video urodynamics [4, 15]. Imaging techniques such as MRI have the advantage of visualisation of the obstruction; however, these techniques cannot be combined with flow studies and are therefore not able to assess the functional component which is most relevant when assessing causes of abnormal PVR [5].

Our main outcome was the presence and extent of obstruction as defined by the Blaivas and Groutz nomogram [6]. The original Blaivas and Groutz nomogram uses maximum flow rate obtained by free flow because in their series a significantly higher flow rate was observed in the same patient without the presence of a catheter [6]. We chose not to analyse maximum flow rate as obtained by free flow as such measurement implicates that the measured values of maximum flow rate and detrusor pressure are based on two separate and potentially different voids as one originates from a void with a catheter and one without. Furthermore, we wanted to minimise the burden for the patients. However, by measuring maximum flow rate with the catheter present, it is possible that we subsequently obtained a relatively low maximum flow rate which might explain part of the high rate of obstruction we found before and after surgery using the Blaivas and Groutz nomogram.

Recently, Massolt et al. also suggested that the Blaivas and Groutz nomogram might overestimate the proportion of patients with bladder outlet obstruction [8]. When using other cutoff points, we would probably have found less obstructed women $[3,4,7,16]$. However, when using these cutoff point studies, one has to realise that only patients with clinically predefined anatomical obstruction were included in these studies, whereas women with functional bladder neck obstruction, e.g. from surgery, were not included in any of these studies [4]. Therefore, the Blaivas and Groutz nomogram might still be the most informative since it graphically shows the difference in flow rates and detrusor pressure which also enables us to see smaller differences between the pre- and postoperative situation.

The main goal of this study was to investigate if anterior colporrhaphy causes bladder outlet obstruction which is hypothesised to be due to urethral elevation or either by suburethral hematoma and/or oedema formation. Using the Blaivas and Groutz nomogram, only one woman appeared to develop obstruction postoperatively, and she was only mildly obstructed after surgery. Also, when looking at the detrusor pressure, no evidence for obstruction could be found since we did not see a rise in detrusor pressure during maximum flow rate. This does not exclude that oedema formation or elevation of the bladder neck might be present; however, our data show that if oedema formation is present, it does not seem to introduce obstruction to the bladder outlet more than the situation before surgery.

In addition, damage to the innervation of the bladder is previously hypothesised as a possible cause for incomplete voiding after prolapse surgery [14]. This would result in a decrease in maximum detrusor pressure and detrusor pressure during maximum flow rate. In women with abnormal PVR, we did observe a trend towards a lower detrusor pressure during maximum flow rate and observed a decreased flow rate. This might indicate that innervation damage may play a role in the development of abnormal PVR. However, an argument against this hypothesis is that within the group of women with abnormal PVR, we could not show a decrease in detrusor pressure during maximum flow rate when comparing detrusor pressure pre- and postoperatively.

Considering the limited evidence that has been provided to support the role of innervation damage on incomplete bladder emptying, and because of the lack of evidence for 
obstruction as a causal factor for incomplete bladder emptying, we think the underlying pathophysiology of voiding difficulties after prolapse surgery should not only be sought in mechanical causes. It is possible that other factors like pain and postoperative anxiety will contribute to this complication $[13,14]$. Support for a possible role of postoperative anxiety came from three earlier randomised studies which all showed a reduction of the postoperative incidence of abnormal PVR after urogynaecological surgery with the administration of alpha blocking agents [17-19]. Further, previous studies have also shown that bladder function impairment could also be explained by psychological inhibition due to the clinical environment in which patients are requested to void postoperatively [17-20]. Therefore, we think that future research should focus more on the origin and treatment of these non-mechanical causes as with the present study and current literature most evidence points towards that direction.

\section{Concluding message}

Urodynamic investigation on the first day after anterior colporrhaphy shows that anterior colporrhaphy carries a low risk of inducing bladder outlet obstruction. The explanation for postoperative development of abnormal PVR should therefore not only be sought in the effects of surgery on the bladder neck and urethra but also involves other nonanatomical explanations such as anxiety, pain and other psychological factors. These possible candidates should be evaluated in order to decrease the prevalence of abnormal PVR and optimise its treatment.

\section{Conflicts of interest None.}

Open Access This article is distributed under the terms of the Creative Commons Attribution License which permits any use, distribution, and reproduction in any medium, provided the original author(s) and the source are credited.

\section{References}

1. Phipps S, Lim YN, McClinton S, Barry C, Rane A, N'Dow J (2006) Short term urinary catheter policies following urogenital surgery in adults. Cochrane Database Syst Rev 19(2):CD004374

2. Lemack GE, Zimmern PE (2000) Pressure flow analysis may aid in identifying women with outflow obstruction. J Urol 163 (6): 1823-1828
3. Di GE, Troyo SR, Aceves JG (2004) Proposed urodynamic pressure-flow nomogram to diagnose female bladder outlet obstruction. Arch Ital Urol Androl 76(2):59-65

4. Akikwala TV, Fleischman N, Nitti VW (2006) Comparison of diagnostic criteria for female bladder outlet obstruction. J Urol 176(5):2093-2097

5. Bombieri L, Freeman RM, Perkins EP, Williams MP, Shaw SR (2002) Objective assessment of bladder neck elevation and urethral compression at colposuspension. BJOG 109(4):395-401

6. Blaivas JG, Groutz A (2000) Bladder outlet obstruction nomogram for women with lower urinary tract symptomatology. Neurourol Urodyn 19(5):553-564

7. Defreitas GA, Zimmern PE, Lemack GE, Shariat SF (2004) Refining diagnosis of anatomic female bladder outlet obstruction: comparison of pressure-flow study parameters in clinically obstructed women with those of normal controls. Urology 64 (4):675-679

8. Massolt ET, Groen J, Vierhout ME (2005) Application of the Blaivas-Groutz bladder outlet obstruction nomogram in women with urinary incontinence. Neurourol Urodyn 24(3):237-242

9. Hakvoort RA, Elberink R, Vollebregt A, Ploeg T, Emanuel MH (2004) How long should urinary bladder catheterisation be continued after vaginal prolapse surgery? A randomised controlled trial comparing short term versus long term catheterisation after vaginal prolapse surgery. BJOG 111(8):828-830

10. Alonzo-Sosa JE, Flores-Contreras JT, Paredes-Canul M (1997) Method for transurethral catheterization for 1-3 days for pelvic floor relaxation in the postoperative period. Ginecol Obstet Mex 65:455-457

11. Ottesen M, Sorensen M, Rasmussen Y, Smidt-Jensen S, Kehlet H, Ottesen B (2002) Fast track vaginal surgery. Acta Obstet Gynecol Scand 81(2):138-146

12. Komesu YM, Rogers RG, Kammerer-Doak DN, Olsen AL, Thompson PK, Walters MD (2007) Clinical predictors of urinary retention after pelvic reconstructive and stress urinary incontinence surgery. J Reprod Med 52(7):611-615

13. Kleeman S, Goldwasser S, Vassallo B, Karram M (2002) Predicting postoperative voiding efficiency after operation for incontinence and prolapse. Am J Obstet Gynecol 187(1):4952

14. Hakvoort RA, Dijkgraaf MG, Burger MP, Emanuel MH, Roovers JP (2009) Predicting short-term urinary retention after vaginal prolapse surgery. Neurourol Urodyn 28(3):225-228

15. Nitti VW, Tu LM, Gitlin J (1999) Diagnosing bladder outlet obstruction in women. J Urol 161(5):1535-1540

16. Lemack GE (2006) Urodynamic assessment of bladder-outlet obstruction in women. Nat Clin Pract Urol 3(1):38-44

17. Lose G, Lindholm P (1985) Prophylactic phenoxybenzamine in the prevention of postoperative retention of urine after vaginal repair: a prospective randomized double-blind trial. Int J Gynaecol Obstet 23(4):315-320

18. Tammela T (1986) Prevention of prolonged voiding problems after unexpected postoperative urinary retention: comparison of phenoxybenzamine and carbachol. J Urol 136(6):12541257

19. Livne PM, Kaplan B, Ovadia Y, Servadio C (1983) Prevention of post-hysterectomy urinary retention by alpha-adrenergic blocker. Acta Obstet Gynecol Scand 62(4):337-340

20. Blok BF, Sturms LM, Holstege G (1998) Brain activation during micturition in women. Brain 121(Pt 11):2033-2042 